\title{
Un análisis sobre la seducción y el acoso en la universidad (San Martín, Argentina)
}

\section{An analysis about seduction and harassment at the university (San Martín, Argentina)}

\author{
Mariana Palumbo (UBA-CONICET) * \\ Belén López (UNSAM)** \\ Melina Pagnone (UNSAM) ***
}

\section{Resumen}

El objetivo de este artículo es, por un lado, describir y analizar comparativamente escenas de acoso/hostigamiento en el marco de situaciones de seducción que tienen como destinatarios/as a varones y mujeres; $y$, por el otro, examinar cuáles son los efectos de las mismas en la construcción de subjetividad femenina y masculina. Se analizan dichas experiencias en estudiantes varones y mujeres de la Universidad Nacional de San Martín, Argentina.

La pregunta que vertebra este trabajo apunta a reconocer los umbrales que llevan de un pasaje del erotismo consentido a situaciones que son percibidas, por los/as estudiantes, como acoso, y qué hacen frente a este hecho. La metodología es cualitativa y se desprende de la realización de entrevistas en profundidad a estudiantes de la Universidad y de la recepción de denuncias sobre violencia contra las mujeres, por parte de la Consejería Integral en violencia de género y sexualidades de dicha Universidad.

Palabras claves: acoso/hostigamiento; seducción; universidad; sexualidad; Argentina

*Dra. en Ciencias Sociales, Socióloga, becaria doctoral del Consejo Nacional de Investigaciones Científicas y Técnicas con sede de trabajo en el Instituto Interdisciplinario de Género y Diversidad Sexual (UBA), Facultad de Filosofía y Letras, Universidad de Buenos Aires. Miembro de la Dirección de Género y Diversidad Sexual (UNSAM).

**Lic. en Antropología Social y Cultural, antropóloga, Instituto de Altos Estudios Sociales, Universidad Nacional de San Martín. Miembro de la Dirección de Género y Diversidad Sexual (UNSAM).

${ }^{* \star *}$ Doctoranda en Sociología, licenciada en Sociología, Instituto de Altos Estudios Sociales, Universidad Nacional de San Martín. Miembro de la Dirección de Género y Diversidad Sexual (UNSAM). 


\begin{abstract}
This article, firstly, describes and analyzes, comparatively, scenes of harassment in situations of seduction that have, as targets, men and women. Secondly, examines what are the effects of these scenes in the construction of female and male subjectivity. This article analyzes those experiences in male and female students from the National University of San Martin, Argentina.

The question that backs up this work is based on what are the thresholds that lead from a passage of eroticism consented to situations that are perceived by the students, as harassment and what do they do with these experiences. The methodology is qualitative, it is based on in-depth interviews to students from this University and the complaints about violence against women, received by the Integral Council on Gender Violence and Sexualities at the University.
\end{abstract}

Keywords: harassment; seduction; university; sexuality; Argentina

Fecha de recepción: Febrero 2019

Fecha de aprobación: Diciembre 2019

\title{
Introducción
}

Las aulas y pasillos, espacios donde transitan gran parte del tiempo los y las estudiantes universitarios/as, son marcos espaciales donde se generan encuentros eróticos- afectivos de diferente tipo y con contenidos diversos que van desde el romanticismo, al encuentro sexual consentido, como así también situaciones de acoso.

Las preguntas que vertebran este trabajo apuntan a reconocer los umbrales que llevan de un pasaje del erotismo consentido a situaciones que son percibidas como acoso, y qué hacen los y las estudiantes de la Universidad Nacional de San Martín (UNSAM) frente a este hecho. Mediante nuestro trabajo de campo y de recepción de denuncias sobre violencia contra las mujeres nos proponemos responder a esas preguntas desde cuatro premisas analíticas. Por un lado, las situaciones atravesadas por escenas de acoso/hostigamiento poseen, en un principio, un contenido de seducción y erotismo. Seguidamente, son percibidas y catalogadas de manera diferente según el género de los actores que realizan la denuncia, la edad, la orientación sexual y según la jerarquía de quien la haya perpetrado y padecido. En tercer lugar, se detectaron tres variables claves que influyen en la percepción del acoso/hostigamiento: la intensidad (que incluye la frecuencia en el intento de acercamiento y la insistencia ante la evasiva o la negativa explícita); la espacialidad donde tiene lugar la escena (que incluye la virtualidad, el anonimato o el acercamiento corporal), especialmente la virtualidad, que emerge como 
un escenario donde se habilitan nuevas formas de "levante" que devienen experiencias de acoso; y también las afectividades que aparecen en el caso, a saber, miedo, incomodidad, humillación. Por último, ante estas experiencias existen diversos tipos de reacciones que van desde preferir no hablar del tema por vergüenza o miedo, no darle importancia 0 tomar la decisión de denunciar ante las autoridades de la universidad o "escrachar" a quien acosó en redes sociales.

El trabajo de campo de esta investigación se ubica en el marco de la Dirección de Género y Diversidad Sexual de la Universidad Nacional de San Martín. Esta Dirección nace en el año 2013 en un contexto más general de avance de políticas públicas contra la violencia hacia las mujeres ${ }^{1}$ a nivel nacional y a raíz del doble femicidio de una estudiante de la Universidad y su madre. En ese entonces, el Programa contra la Violencia de Género, hoy Dirección de Género y de Diversidad Sexual, interviene en casos de discriminación y violencia de género tanto de la propia Universidad como provenientes de la comunidad del Partido de General San Martín y zonas aledañas. Dentro de la Dirección de Género y Diversidad Sexual funcionan tres consejerías: la Consejería de Atención de la Violencia de Género, la Consejería Integral en Sexualidades y la Consejería en búsqueda de personas.

El Protocolo para la actuación en situaciones de violencia y/o discriminación por razones de género u orientación sexual, creado en el 2015, constituye la principal normativa que posee la universidad para actuar frente a situaciones de violencia de género o discriminación. Dicha normativa contempla medidas preventivas o pedagógicas, de protección y de investigación de los hechos denunciados, pasibles de ser sancionados. Si bien el accionar de la Consejería tiene como principal objetivo la prevención y protección más que la investigación o sanción de los hechos, resulta fundamental aclarar que, como la mayoría de los reglamentos, tiene un sesgo en su aplicación porque la investigación de los hechos depende, entre otras cosas, de la voluntad expresa de quien denuncia. Esto resulta problemático porque es menos probable que un/una estudiante denuncie a su docente $o$ a alguna autoridad que a un par. Aunque no poseemos datos cuantificables que nos permitan observar esta relación, una de nuestras hipótesis es que la jerarquía de quien violenta influye en la decisión de denunciar (o no) debido a la exposición que ello puede significar para la persona denunciante.

Teniendo en cuenta el contexto anteriormente explicitado, el objetivo de este artículo es, por un lado, describir y analizar comparativamente escenas de acoso/hostigamiento en el marco de situaciones de seducción que tienen como

\footnotetext{
${ }^{1}$ En el año 2009, el Estado argentino promulgó la Ley 26.485 de "Protección Integral para prevenir, sancionar y erradicar la violencia contra las mujeres". Dicha ley es una de las conquistas del movimiento feminista y de mujeres en la puja por una mayor igualdad entre los géneros y una mejor convivencia de la sociedad toda. En el marco de este avance, en relación con la temática de violencia contra las mujeres, cuatro años más tarde, en el año 2013, nace el Programa contra la violencia de género en la Universidad Nacional de San Martín.
} 
Revista Punto Género № 12. Diciembre de 2019

ISSN 0719-0417 / 48 - 72

destinatarios/as a varones y mujeres; y, por el otro, examinar cuáles son los efectos en la construcción de subjetividad femenina y masculina.

Partimos de considerar que los guiones de seducción se inscriben dentro de los postulados románticos que operan moldeando la forma del cortejo (Palumbo, 2018), los cuales están basados en las dinámicas de citas, la muestra de deseo y en prácticas violentas, que conforman lo romántico, como por ejemplo los celos y el control (Marentes, Palumbo y Boy, 2016)

\section{Metodología}

La metodología del artículo es de tipo cualitativa. Se realizaron 20 entrevistas en profundidad a varones y mujeres cis como así también a mujeres trans y travestis que 
Revista Punto Género № 12. Diciembre de 2019

ISSN 0719-0417 / 48 - 72

actualmente estudian carreras de grado en la Universidad Nacional de San Martín (UNSAM)2. Los/as entrevistados/as son jóvenes (de entre 20 y 40 años) y tienen distintas orientaciones sexuales. Algunos/as están solteros/as y otros/as se encuentran en algún tipo de vínculo erótico-afectivo. Respecto a las disciplinas donde se desempeñan, cursan carreras en distintas unidades académicas de la Universidad ${ }^{3}$.

Tabla 1. Muestra de entrevistados/as

\begin{tabular}{|c|c|c|}
\hline Género & Orientación sexual & Tipo de vínculo erótico-afectivo \\
\hline Mujer Cis & Heterosexual & De novia, convive \\
\hline Mujer Cis & Heterosexual & De novia \\
\hline Mujer Cis & Lesbiana & De novia \\
\hline Mujer Cis & Bisexual & Soltera \\
\hline Mujer Cis & Bisexual & De novia \\
\hline Mujer Cis & Heterosexual & De novia \\
\hline Mujer Cis & Heterosexual & "Saliendo con alguien" \\
\hline Mujer Cis & Bisexual & De novia \\
\hline Mujer Cis & Bisexual & De novia \\
\hline Mujer Cis & Heterosexual & De novia \\
\hline Mujer Trans & Heterosexual & Soltera \\
\hline Travesti & Fluida & Soltera \\
\hline Varón Cis & Heterosexual & Soltero \\
\hline Varón Cis & Bisexual & Soltero \\
\hline Varón Cis & Heterosexual & De novio, convive \\
\hline Varón Cis & Heterosexual & Soltero \\
\hline Varón Cis & Gay & Soltero \\
\hline Varón Cis & Heterosexual & Soltero \\
\hline Varón Cis & Heterosexual & De novio, convive \\
\hline
\end{tabular}

2 El artículo se enmarca en un Proyecto de Reconocimiento Institucional de la Universidad Nacional de San Martín, provincia de Buenos Aires, Argentina, denominado "Representaciones sociales y experiencias en torno a la violencia de género y sexualidades en estudiantes, docentes y no docentes de la Universidad Nacional de San Martín" que tiene vigencia desde el 2017 al 2019.

${ }^{3}$ Se realizaron entrevistas de manera ponderada según la cantidad de estudiantes de cada unidad académica. Las unidades académicas seleccionadas fueron: Artes, Ciencias Sociales, Humanidades, Ciencia y Tecnología, Economía y Negocios, Transporte y Salud. Los nombres de las entrevistas fueron modificados por seudónimos. 
Revista Punto Género № 12. Diciembre de 2019

ISSN 0719-0417 / 48 - 72

\section{\begin{tabular}{l|l|l} 
Varón Cis & Heterosexual & De novio
\end{tabular}}

El guion de las entrevistas fue semiestructurado, los ejes versaron en: a) la trayectoria socio-educativa de los/as entrevistados/as; b) trayectoria afectiva y familiar; c) situaciones de violencia, de diverso tipo, dentro de sus vínculos eróticos y/o afectivos ${ }^{4} ; \mathrm{y}$ d) sociabilidad con personas del ámbito universitario, tanto en las aulas y pasillos de la Universidad como en ámbitos virtuales.

Una segunda fuente de datos son las narrativas de las denuncias de casos de acoso que vivenciaron estudiantes, en el marco de escenas de seducción, que se reciben dentro de la Consejería en Violencia de Género y Sexualidades Dirección de Género y Diversidad Sexual de la UNSAM, en tanto las tres de las autoras de este trabajamos somos integrantes de dicho espacio. Dichas denuncias son trabajadas, a los fines de este artículo, de manera anónima y sin dar ninguna información sensible sobre los casos. En rasgos generales la población que denuncia son mujeres, cis y trans heterosexuales, estudiantes, docentes y no docentes, de distintas edades, que sufrieron violencia por parte de varones. Específicamente, entre las consultas recibidas en la Consejería desde febrero de 2016 a junio de 2019 , el $90 \%$ de las personas consultantes son mujeres cis, el $6 \%$ varones cis y el $4 \%$ feminidades trans. La mayor parte de las/los consultantes se concentran en la franja etaria que va de 17 a 25 años (40\%) y de 26 a 35 años (27\%).

Para el trabajo analítico con el corpus de las entrevistas de esta investigación nos valimos de la metodología de las escenas de Vera Paiva (2006). La noción de escena de la autora es un recurso fértil para explorar sobre las experiencias cotidianas de las personas. Durante las entrevistas se les solicitó a los/as entrevistados/as que relaten las distintas situaciones de acoso como si fuera una escena de una película, es decir, brindando la mayor cantidad de detalles posibles sobre cómo era el escenario, qué objetos intervenían, cómo se sentían, entre otras cuestiones descriptivas. Esto permitió que no sólo den pauta de sus creencias y representaciones, sino que también indiquen qué otros actantes -entendidos como personajes o fuerzas impersonales que habilitan 0 no acciones y relaciones de la persona (Meccia, 2012)- interactúan, las prácticas concretas, los objetos con los cuales seducen o con los cuales rechazan, cuál era el escenario de la acción y sus secuencias temporales.

Las escenas permiten organizar el recuerdo sobre lo sucedido, no obstante, tal como indica Paiva, éstas son únicas y nunca son narradas de la misma forma. Dice la autora: "decodificarla aumentará la probabilidad de modificarla" (Paiva, 2006: 32). Otras apuestas sugeridas por la autora y que son enriquecedoras para la descripción de una

\footnotetext{
${ }^{4}$ Respecto al planteo de "encuentros eróticos y/o afectivos", tiene como finalidad dar cuenta de la variedad de vínculos que establecen los sujetos en el nivel afectivo. Las personas entrevistadas pueden o no estar en pareja. Aparecen una variedad de relaciones de tipo eróticas, que pueden incluir sólo encuentros sexuales, con una o más personas, y otras que no conllevan tener relaciones sexuales como compañía o flirteo.
} 
escena son ejercicios imaginarios de ponerse en el lugar del otro sujeto presente durante el transcurso de la escena relatada: que el/la entrevistado/a imagine que se observa a sí mismo por fuera de una escena de la cual es parte, es decir que se abstraiga de la escena que relató y la explique como si fuese alguien externo. En el caso de esta investigación, este último punto fue realizado en algunos casos y permitió a los/as entrevistados/as indagar sobre lo tolerable y admisible para ellos en relación con los guiones de seducción. Esto tiene como objetivo subyacente estimular el conocimiento sobre el contexto social de los escenarios dentro de los cuales los/as entrevistados/as pueden desenvolverse, como así también lograr cierta reflexividad sobre sus interacciones.

\section{¿Cuáles son los límites entre la seducción y el acoso?}

Para explicar qué entendemos por seducción diríamos que son prácticas realizadas por una persona con el fin de indicarle a otros/as que está interesado/a erótica y/o afectivamente en él/ella. La seducción se encuentra atravesada por dinámicas eróticas que exceden lo sexual y, explica Illouz (2012) oscilan entre la exhibición y el ocultamiento, la privación y la satisfacción (erótica). Illouz retoma a Barthes (2007) para quien lo erótico es intermitencia; "es la intermitencia, como bien lo ha dicho el psicoanálisis, la que es erótica: la piel que centellea entre dos piezas (el pantalón y el pulóver), entre dos bordes (la camiseta entreabierta, el guante y la manga), es ese centelleo el que seduce, o mejor: la puesta en escena de una aparición-desaparición" (Barthes, 2007: 9-10 en Illouz, 2012: 245).

En una misma línea que apunta a lo difuso del erotismo, entre lo que aparece y desaparece, nos encontramos con el texto clásico de Georg Simmel (2003) sobre la coquetería. El autor analiza a la coquetería como un guion de seducción basado en la idea de quizás, es decir un juego de aceptar y rechazar. Desde esta idea del quizás, atravesada por la ambigüedad y la sutileza de indiscernible, entendemos que ciertas prácticas de seducción pueden quedar en la deserotización, devenir en un potencial encuentro erótico o pendular hacia situaciones de acoso.

Ante ese quizás simmeliano, un concepto que viene a responder, en principio, a la violencia masculina que se encubre en la seducción es el consentimiento. Esta noción apela al lema, del cual se ha apropiado fuertemente el feminismo de la cuarta ola $\operatorname{argentino}^{5}$, de "No es No". Este ideario en boga encuentra ciertas limitaciones desde el análisis que realiza Pérez Hernández (2016). Para esta autora mexicana, el

\footnotetext{
${ }^{5}$ Matos (2010) ubica al feminismo de la cuarta ola en Latinoamérica a partir del año 2000. Este se define por la profundización y ampliación de los derechos humanos y por la amplia presencia de mujeres en lucha en el espacio público. El sentido orientador dentro de esta nueva ola aparece en un renovado énfasis en las fronteras intersectoriales, transversales y multidisciplinares. Asimismo, un aspecto nodal en esta cuarta ola es la emergencia de la virtualidad como forma de resistencia y activismo feminista (Cochrane, 2013).
} 
consentimiento apela a un sujeto volitivo que, a partir de la expresión verbal (o su ausencia), admite o no una cierta práctica erótica. Subyace una perspectiva psicologizada del consentimiento que desconoce los marcos culturales y las relaciones de poder donde "ese sí o ese no" se desarrollan, a la vez que deposita en la palabra la determinación de las dinámicas de seducción, las cuales sobrepasan el mero registro verbal. Por su parte, Butler (2011) también problematiza la noción de consentimiento y nos invita a reflexionar sobre la estabilidad del consentimiento del yo y de los cambios que se producen en el curso del consentimiento.

Desde una perspectiva de las ciencias sociales, en la cual nos enmarcamos, nos preguntamos por las jerarquías de las personas involucradas al momento de la seducción, los deseos y agencias de las personas, en qué marco sexo-genérico se desarrolla la interacción, los espacios, las negociaciones que existen, la trayectoria socioeconómica de las personas involucradas, la edad, entre otras cuestiones que nos permitan visualizar los marcos sociales donde tiene lugar la seducción. Retomamos la lectura de Peréz Hernández (2016) sobre las feministas estructural-constructivistas (Moore y Reynolds, 2004), quienes se alejan de las visiones deterministas y victimistas de las feministas radicales como así también de los post-feminismos que poseen una visión excesivamente racionalista sobre la temática del consentimiento, en tanto consideran que las mujeres son agentes sexuales con capacidad plena de ejercer sus decisiones libremente, de manera autónoma y responsable. Para las estructural-constructivistas, incluida la perspectiva de Pérez Hernández, es necesario analizar al consentimiento teniendo en cuenta "la desigualdad social basada en la diferencia sexual, planteando tensiones entre los procesos sociales, las determinaciones estructurales y la agencia femenina" (2016: 755).

Desde una lectura interseccional de los guiones sexuales, que aquí nos planteamos, retomamos la apuesta de Bryana French (2012) quien analiza estos scripts en relación con la raza y el género. En su estudio examina las representaciones en torno a experiencias de presión y coerción sexual en adolescentes afro americanas por parte de varones, y las respuestas que esbozan ante las mismas. La autora considera que la agencia de estas jóvenes ante dichas situaciones está signada tanto por los estereotipos históricos que recaen sobre sus corporalidades como por otros repertorios que los confrontan. Siguiendo a French, resulta importante trabajar con una mirada interseccional para atender de forma integral a los diversos guiones sexuales que van dando forma, según cada sujeto y contexto, a los límites entre el acoso y la seducción.

Asimismo, desde un análisis socio antropológico, contra aquellos más psicologizantes, nos preguntamos por las tramas que hacen que el balance de una situación de seducción pueda devenir acoso. Dejamos de lado aquellas escenas que terminan en las violencias más cruentas y explícitas de tipo sexual y física, y ponemos el foco en los umbrales de la seducción y cuáles son los efectos que generan en las personas involucradas. Es decir, analizaremos el acoso como categoría etnográfica para intentar comprender el sistema de valores en el cual se inscribe en estas circunstancias. 
Respecto a la trama de la seducción, identificamos en las escenas tres hitos nodales: la insinuación, el tiempo de respuesta a la misma y la respuesta en sí. Estos tres eventos, a la luz de la metodología de las escenas de Paiva quien propone un análisis minucioso de los escenarios y sus secuencias, poseen ciertas intensidades, temporalidades y afectividades. En relación con la intensidad, comienza a aparecer la idea de acoso cuando una de las partes tiene una presencia física y/o virtual excesiva, por ejemplo puede ser que alguien con quien se cursa materias no tenga relación cara a cara, pero que por redes sociales dé like (me gusta) a todas las fotos o escriba insistentemente por chat.

Los umbrales de espera también son un indicador para las personas entrevistadas de una señal de acoso; por ejemplo, en lo virtual, la reiteración en la comunicación cuando aún una de las partes no responde. Cuando hay sinergia entre las partes, en términos de Collins (2009), la situación de seducción continuará, no obstante puede ser que en algún momento de la construcción del vínculo se dé un pasaje de la seducción al acoso. En los casos donde la intensidad y los tiempos de las partes no coinciden, puede aparecer un pasaje de la seducción al acoso, signada por el miedo al otro. Esta emoción actúa generando reacciones, las cuales serán problematizadas en el último apartado, que van desde el silencio a aquellas que activan redes de contención familiares $\mathrm{y} / \mathrm{o}$ institucionales, por ejemplo pedir asesoramiento o denunciar en la Dirección de Género y Diversidad Sexual de la UNSAM.

Las intensidades, temporalidades y afectividades que balancean la seducción tienen lugar dentro de un contexto más amplio, tal como indicamos, y no operan de igual manera en todos los casos. Sin embargo, consideramos que funcionan como marcos que delinean los umbrales entre la seducción y el acoso.

Por último, en la seducción los sujetos crean situaciones de intimidad o proximidad corporal (Simmel, 2003). La idea desde la cual partimos en el análisis del cuerpo entiende a la corporalidad más allá de los límites de la piel. En el contexto actual de proliferación de sociabilidad a través de las redes sociales, la corporalidad, tal como explica Donna Haraway (1991), trasciende los dualismos modernos entre yo y otro, cuerpo y mente, humano y animal, humano y máquina. Las nuevas tecnologías cibernéticas habilitan límites fluidos que generan sujetos y organismos híbridos que pueden ser englobados bajo la metáfora del cyborg. A los fines de la seducción, la virtualidad pasa a ser un terreno fértil para generar estrategias de seducción; por ejemplo, el mayor anonimato habilita nuevos guiones y agencias en la seducción en ámbitos virtuales (Kaufmann, 2012).

\section{Seducción-Acoso en clave interseccional}

En este apartado analizamos diversas escenas en torno a situaciones de seducción y acoso teniendo en cuenta el contexto en el cual se originaron, el género, la orientación sexual y las jerarquías de las personas involucradas. 
Julia es una estudiante de 25 años, cursa en la universidad hace 6 años, y ha atravesado situaciones de violencia tanto con su ex pareja (padre de su hija) como con compañeros "machirulos", tal como ellas los denomina. Su activismo en la temática feminista dentro de la universidad la llevó a tener distintas situaciones de confrontación con sus compañeros cis varones. En la Escuela a la cual pertenece su carrera, participa de proyectos de extensión universitaria, espacio donde conoció a su actual pareja. Ella se define como bisexual y remarca que la universidad es uno de los pocos espacios donde dio a conocer su orientación sexual, hecho que despierta "el morbo" en algunos de sus compañeros quienes al enterarse la instigaron con preguntas en torno a sus prácticas sexuales, a diferencia de lo que les sucede a sus compañeras heterosexuales.

A continuación desarrollamos dos escenas de seducción experimentadas por Julia. Una devino en una merma de la energía emocional entre las partes y una segunda terminó siendo percibida por ella como acoso. El primer caso tuvo lugar con un compañero de cursada. Todo comenzó durante largas jornadas de estudio en el café de la Escuela. En ese ida y vuelta comenzó a haber "onda" entre ellos. Ella tomó la iniciativa y lo invitó a salir. Desde ese momento sus encuentros se dieron por fuera del espacio universitario. En este punto se torna interesante indagar en "el estudio", entendiéndolo metodológicamente desde los análisis de Appadurai (1986), donde al perseguir la circulación del objeto/la cosa (en este caso la tarea y la lectura de los textos universitarios brindados por el plantel docente en el programa de la materia) encontramos distintas formas de vinculación social entre los actores del campo. En distintas escenas descritas por las/los entrevistadas/os, "el estudio" se torna un objeto apacible de generar una situación propicia para vincularse sexualmente con otro/a par universitario/a. Las reglas del juego de seducción establecidas aquí parecen demarcar una delimitación espacial entre el adentro y el afuera de la universidad. Dentro de la universidad existe un nicho de potenciales compañeros/as sexo-afectivas/os, pero la acción concreta tiene como escena principal el "afuera". Fue siguiendo este guion que Julia comenzó a verse con su compañero, pero la frecuencia y la intensidad del vínculo, en términos románticos, era poca. A veces pasaba un tiempo largo hasta que volvían a encontrarse a estudiar por fuera de la universidad, donde terminaban teniendo sus encuentros sexuales.

La segunda escena, que comenzó como seducción y devino en acoso, tuvo lugar entre Julia y un docente. Ella tiene una estrecha relación con el plantel docente que imparte las materias sociales y humanas. Julia explica que suele haber "buena onda" entre los y las estudiantes que eligen este tipo de materias, en el marco de una carrera que se basa en asignaturas relacionadas con la contabilidad y la matemática. A lo largo de su trayectoria en la universidad, Julia indica que si bien con los docentes de materias sociales tuvo distintas actividades por fuera del ámbito universitario (bares, marchas, plazas), jamás sintió que hayan buscado avanzar en términos de seducción para con ella. No obstante, en una oportunidad un docente intentó seducirla. El docente, al enterarse que ella milita por fuera de la universidad, le ofreció ayuda y comenzó a acompañarla en su espacio de activismo. En ese marco, él la invitó a tomar un café, como modo de acercarse a ella y poder hablar de sus vidas. Tanto acercamiento la hacía sentir 
incómoda. Ella se negó a ir a tomar un café con él. Ante esta negativa, él comenzó a ser insistente. El hecho que el docente la cite por fuera de los espacios de la universidad hizo que ella comience a sospechar que tenía intenciones de acercarse sexo-afectivamente hacia ella.

Esta escena, Julia la asocia a otras actitudes que él tenía con ella, como cuando le tocaba el hombro mientras le hablaba durante sus encuentros y clases en la universidad. Su mayor desconcierto e incomodidad surgió cuando él empezó a hablarle insistentemente por Facebook a altas horas de la noche. Esto le generó -en términos de la propia entrevistada- una sensación de repulsión, y, antes de bloquearlo de su cuenta decide no hablarle más y le envía el último mensaje por Facebook: "me parece que estás desubicándote totalmente" y presionó el botón de envío. Nunca más se volvió a vincular con él. Tal como desarrollaremos en el próximo apartado, esta situación de acoso llevó a que ella dejase la materia y decidiese reinscribirse en otra cátedra, asegurándose así no volver a encontrarlo. Si bien pensó en hablar con las autoridades, decidió no hacerlo porque se encontraba en sus primeros pasos de la carrera, el docente le había indicado que tenía una alta reputación en el extranjero y ella tenía temor de las repercusiones que eso pudiera generar: "capaz después me la tiene jurada, ¿viste?, y me desaprueba o alguna cosa así...".

Es interesante destacar algunos factores que se desprenden de la experiencia vivida por Julia y que marcan el traspaso de un umbral entre la seducción y la situación de acoso, en este caso vinculado a la repulsión y el temor. Por un lado, cabe problematizar la manera en la que el (no) consentimiento se pone en juego. Retomando las reflexiones de Pérez Hernández (2016) sobre la manera en la que la sentencia "no es no" como respuesta del feminismo corre el riesgo de anular otras expresiones en torno al consentimiento sexual, respecto de la intensidad, Julia estableció límites no verbales al docente que quiso seducirla. El "no", para ella, fue la última instancia para mostrar su falta de consentimiento. Respecto de la espacialidad, apareció su posicionamiento corporal, firme ante los intentos de acercamiento corporal por parte del docente durante clase: ella respondía con rigidez ante la incomodidad que eso le generaba. En segunda instancia, se negó a encontrarse con el docente por fuera de la espacialidad de la universidad. Este "no" resulta entonces como una negativa indirecta. Como bien indicamos anteriormente, el encontrarse por fuera de la universidad con un/a miembro/a de la comunidad universitaria es sobreentendido como señal de avance en términos de seducción. Aceptar o no aceptar encontrarse por fuera de la universidad es entendido como posibilidad (o imposibilidad) de continuar vinculándose con otra persona de una manera sexual y/o afectiva. De esta forma, el hecho de que Julia se negara a encontrarse con el docente que le insistía para verse por fuera de la escuela, era un precedente de su falta de interés hacia él. La acumulación de precedentes que demostraban su falta de consentimiento estalló luego de la insistencia del docente en las redes sociales. Este último aspecto puede brindar un puntapié para indagar en los distintos niveles de gravedad en las situaciones de acoso.

Cuando hablamos de niveles de gravedad no sólo nos referimos, en términos cuantitativos, a la cantidad acumulada de negativas "no verbales" que recibe la persona 
acosada, sino también al tipo de límite que el/la acosador/a traspasa con cada avance, por ejemplo, que él le toque la cintura. En este aspecto la espacialidad actúa aumentando o no la gravedad del hecho. Por ejemplo, los casos donde el cortejo indeseado se da dentro de la universidad podemos considerarlos como "más graves", en tanto este es un ámbito que se presupone seguro y donde las jerarquías se encuentran más visibles.

A su vez, otra regla social sobre la seducción tiene que ver con la cuestión jerárquica que posee el vínculo docente-estudiante. La lectura del encuentro por fuera de la universidad es entendida más fácilmente como señal de deseo sexo-afectivo, y cuando esto último sucede entre docente-estudiante la reacción se torna más repulsiva. Esto se vincula a lo relatado por Ramiro, un estudiante homosexual, quien aseguraba que el hecho de existir entre ambos una relación jerárquica implicaba que el docente (en este caso quien poseía poder en términos de jerarquía frente al estudiante) se encontraba "abusando" de ese vínculo.

Aquí las percepciones sobre el acoso exceden el sexo y la orientación sexual del entrevistado y se relacionan más con el tipo de posición que ubica a una persona dentro de la jerarquía del sistema educativo. Distinta es la percepción de la seducción entre pares, donde no se percibe acoso, en términos generales, en la instancia de acercamiento.

Vanina, una estudiante travesti de 39 años, relata que luego de sucesivos intercambios vía chat con un docente varón accedió a tener un encuentro sexual consentido, pero inmediatamente luego del suceso, el profesor le quita el saludo, "le da vuelta la cara" en el espacio universitario, algo que ella percibe como violento.

Luego de los intercambios -ya sean virtuales y/o cara a cara- propios de las instancias de seducción, los vínculos pueden devenir al plano de la formalidad, de lo esporádico -touch and go- o concluir en un único encuentro sexual. Según Vanina, y aunque ella no tuviera intenciones de formalizar ese vínculo, su identidad travesti incidió en el hecho de que el docente le quitó el saludo. Según ella, posiblemente una chica cis heterosexual no hubiese corrido la misma suerte (en relación con la negación del saludo). Vanina comenta, en cuanto a la posibilidad de un posible vínculo afectivo (pos proceso de coqueteo) "en lo afectivo, aunque le caigas bien al tipo, no se lo permiten" (en relación con cómo su género repercute en el desenlace del "flirteo" en vínculo afectivo o no). "Blanquear una relación con una chica trans tiene un costo". En términos de la estudiante, su identidad de género al estar estigmatizada socialmente conlleva un "peso" para la otra persona al momento de afrontar y hacer visible un vínculo (o simplemente sostener un saludo). Ese "costo" puede estar vinculado al cuestionamiento de la otra persona respecto a su masculinidad cis heterosexual.

Siendo un docente quien niega el saludo luego del encuentro sexual, alguien ubicado en un lugar de privilegio, esta actitud hizo que Vanina se alejara de los espacios que habitaba el profesor y consecuentemente abandone la materia dictada por él. Aunque dicho encuentro sexual entre un docente varón y una estudiante travesti haya sido de mutuo acuerdo, según el relato de Vanina su identidad de género ponía en juego "otras 
cosas" en el docente, al punto de repercutir en el momento pos encuentro sexual: "un saludo no se le niega a nadie", indica Vanina.

La vivencia de Vanina nos invita a pensar en cómo las desigualdades de género, en este caso entre las feminidades hegemónicas y la identidad travesti, repercuten en el momento posterior a la instancia de seducción y al encuentro sexual. En este caso, a partir del retiro del saludo, quizás como una manera de "no dejar rastros" que vinculen al docente con la estudiante travesti, es posible pensar cómo la heterosexualidad configura las relaciones sociales (en este caso, "quien merece un saludo y quien no") dentro de la institución.

En relación con situaciones de acoso desde la virtualidad, observemos los casos de Dana y Agustina. Ellas son dos estudiantes de la Escuela de Humanidades que recién comenzaban la universidad y se acercaron al espacio de Consejería, ya que se sentían acosadas por un estudiante que las contactaba vía chat de Whatsapp y Facebook para escribirles mensajes románticos. Ambas señalaron que, además de sentirse acosadas, lo que les generaba más temor era no haber hablado nunca cara a cara con él y que muchas veces las contactara desde múltiples usuarios virtuales anónimos. Más allá de la situación violenta presente en este caso, donde el estudiante las contactaba insistentemente sin respetar los impases que ellas ponían, ambas remarcaron la impotencia que les generaba no saber quién se encontraba detrás del usuario y la imprevisibilidad de saber cuándo llegaría el próximo mensaje. Aquí, nuevamente las variables de la intensidad (tanto la frecuencia del contacto como el no respeto de las negativas cada vez más explícitas) y la espacialidad, en este caso definida por la virtualidad y el anonimato juegan un rol fundamental en la percepción de la situación como acoso por parte de la estudiantes.

Algo similar sucedió con Mariana, otra estudiante de Ciencias Sociales, joven, activista y recientemente ingresada a la universidad, quien se acercó a consultar qué hacer ante situaciones de acoso por parte de un profesor. Respecto a la intensidad, ella cuenta que su perfil de Instagram era público y él le ponía like a todas sus fotos. La entrevistada resaltó en su testimonio que lo hacía con fotos "que nada que ver", como una imagen donde estaba en bikini con una amiga en una pileta. En este caso, la intensidad se refleja en el hecho de que puso like en "demasiadas" fotos. También le había ofrecido darle un libro por el chat de Facebook y ella no quería aceptarlo, por temor a que la malinterprete. Había dejado de cursar la materia del docente en cuestión, pero ella necesitaba la firma de él en la libreta y eso la incomodaba. Respecto a la espacialidad, nuevamente aparece el ámbito virtual como escenario central en la experiencia del acoso. El cortejo por redes sociales aumenta la ambivalencia y las dudas sobre la situación, lo cual genera malestar en la estudiante. Ella se siente incómoda ante un docente que se encuentra en otra jerarquía dentro de la estructura universitaria, por lo cual se acerca a consultar al espacio de contención que posee la universidad.

En el caso de Sonia, una estudiante bisexual de Ciencias Sociales que entabló una relación sexo-afectiva con otra compañera, se dio de manera distinta. Si bien la 
virtualidad es remarcada por ella como una "megapresencia", las situaciones que atravesó, antes de acercarse a la consejería a consultar, fueron mayores en cantidad e intensidad. Aquí, el reconocimiento de las actitudes de su compañera como situaciones de acoso se dio de manera más tardía. Este hecho llama la atención ante una forma diferencial de actuar frente al acoso debido a que se trata de dos mujeres.

Retomando el concepto de pánico sexual de Marta Lamas (2018), cabe preguntarse si esta diferencia entre la rapidez de las reacción de las chicas para con sus "acosadores" varones y la "tardanza" de la denuncia ante un caso de acoso de una mujer hacia otra mujer, tiene que ver con el ideario de victimario varón, lo cual vuelve difícil de desprender de la corporalidad masculina y asimilarlo a la femenina.

Aquí es pertinente traer la experiencia de Guido, otro estudiante de la Escuela de Ciencia y Tecnología, bisexual, para indagar en la diferencia sustancial que se presenta ante la decodificación de las instancias de seducción como acoso, cuando el "decodificador" es varón. En su caso atravesó dos escenas que describió como incómodas pero que no conceptualizó como situaciones de acoso propiamente dichas. Una de ellas se trató del acercamiento de una compañera que buscaba tener sexo con él y le enviaba fotos de ella desnuda. Esto, si bien lo incomodaba, no le generaba mayor preocupación, "estaba todo bien" y no se lo "tomó a mal". La segunda escena se trató de un compañero adscripto a una materia con quien cursaba. Él empezó a "tirarle palos" subiendo comentarios, videos e imágenes públicas. Por ejemplo, pegó en el muro de Facebook de Guido, el video de una canción de la banda de música Miranda, cuya letra dice: "yo quiero ser tu profe, mejor dicho profesor, el que te enseñe del amor, lo que sabes y disimulas, quisiera que me mientas cuando pregunte tu edad, quiero volverme tan vulgar, voy a engañarte tonta, solo para tocarte un poco". Frente a esta situación que "lo ponía incómodo", resaltando la reacción de sus amigos en los comentarios del posteo, indicó que al mismo tiempo no lo ofendía, y que lo tomaba con humor.

Con esta escena como contraste se puede inferir que en aquellos casos donde quien es "acosado" es un varón, la acción ni siquiera se interpreta como tal. Como bien sostiene Lamas (2018), el pánico sexual se encuentra vinculado con los imaginarios en torno a la sexualidad femenina y masculina, donde el dominio lo tiene el varón. En el caso de Guido, donde se trata de una situación de acoso virtual entre dos varones, pensarse como víctima sería correrse de ese imaginario. Algo que evidentemente no le sucedió. En sintonía con esta línea analítica, Sonia identifica en su pareja mujer un acoso que es asimilado por ella a la figura masculina:

"Me mandaba videos de una cantante, algo así como muy romántico, que es como Arjona mujer. Y después mandaba mensajes 'te odio', mensajes 'te amo', mensaje 'sos una mierda', mensajes 'te extraño', como un macho de manual, ¿entendés?, cosas que escuchaba por la consejería (en violencia de género de su espacio de militancia). Como... ¿por qué me está pasando esto?" 
En este caso de acoso se generó una ruptura con el ideario de varón acosador, es decir, la acción violenta, masculina, es perpetrada por una mujer cis. Esto lleva a preguntarnos por la manera en que ciertos comportamientos propios de la masculinidad hegemónica pueden llegar a ser perpetrados, en ciertos contextos, entre mujeres. El análisis de Connell (1995) sobre la manera en la cual el género no se reduce a una corporalidad específica, se torna fundamental para pensar estas cuestiones en el caso de las/los perpetradoras/os de violencia.

Es decir, la mujer puede masculinizarse en situaciones de acoso. La pareja de Sonia es interpretada por ella como "macho de manual", y si bien tarda más en denunciarla que en los casos donde el acoso era perpetrado por un hombre a una mujer, lo termina realizando. Distinto sucede entre dos varones, donde esa ruptura de la corporalidad asociada a la masculinidad no tiene lugar. Podría inferirse que los idearios de "víctima" se tornan más complejos de separar con las ataduras culturales que posee la figura femenina $u$ otras alejadas de la masculinidad.

Este apartado denota distintas representaciones sobre los umbrales entre la seducción y el acoso, se vislumbran límites propios del ámbito académico conformados por las y los estudiantes. En primera instancia, las actividades académicas ofician como actantes del cortejo y esto hace confluir distintos factores que hacen que la situación se interprete como una mera seducción o como acoso. Un aspecto fundamental tiene que ver con el tipo de relación jerárquica que existe entre las dos personas involucradas en el cortejo. Si quien avanza sobre el/la estudiante es docente, este/a primero/a no lo percibe de igual manera que si se tratara de un par. Otro factor detectado se vincula a la espacialidad de los encuentros. Por ejemplo, si ese/a docente con quien el/la estudiante mantiene encuentros con motivos académicos, le propone encontrarse por fuera de la universidad o le habla insistentemente por redes sociales, el/la estudiante comienza a asimilar ese vínculo al acoso.

En segunda instancia, se puede inferir que existen diferenciaciones entre las representaciones esbozadas sobre quien acosa y quien es acosado/a, que dependen del género manifestado por cada uno/a. Esto quiere decir que, por un lado, no se toma de igual manera una situación de acoso entre varones, entre mujeres y/o entre personas de distintos géneros. Como así tampoco se sostienen los mismos guiones sexuales de forma unánime, sino que estos se reconfiguran dependiendo de las distintas opresiones que se interseccionan en cada caso -orientación sexual, género, jerarquías e identidad sexual(French, 2013; Ronen, 2010). Y por otro, el género en sí no siempre queda sujeto a la corporalidad y al estereotipo sexual asociado socialmente a la misma, sino que este puede variar y ser asociado a acciones puntuales, como lo es una escena de acoso.

\section{Reacciones ante las situaciones de acoso}


En este apartado nos proponemos reflexionar acerca de los modos en que los/las estudiantes reaccionan frente a las diferentes situaciones de acoso/hostigamiento que tienen lugar en el marco de seducción o acercamientos sexo/afectivos.

Existen formas de violencia que se expresan de manera clara y cruenta. Sin embargo, resulta interesante pensar en las actitudes que tenemos o cómo nos paramos frente a diferentes situaciones que nos incomodan y que se encuentran cercanas al límite entre la seducción y el acoso.

En estas situaciones existe mayor incertidumbre y ambivalencia tanto en la interpretación de la situación, como también en la reacción o respuesta que desencadena. Así como hay quienes viven estas situaciones con naturalidad, quienes las viven con incomodidad y quienes las sienten violentas, existen diferentes reacciones que van desde no contarle a nadie, denunciar, "escrachar" en redes sociales, acudir a familiares/amigas/os por ayuda o a especialistas para preguntar cómo deberían sentirse y por ende reaccionar.

A lo largo de este apartado reflexionamos acerca de los factores que influyen o condicionan las reacciones ante una situación de acoso/hostigamiento en el marco de la seducción. Nos preguntamos si las diferentes respuestas tienen que ver con una evaluación de las características de los acontecimientos, por ejemplo, la insistencia; con una evaluación de la persona que los propicia, como por ejemplo, su jerarquía, edad o si se trata de una persona violenta; el contexto actual de efervescencia de la temática y la disponibilidad de dispositivos de atención y bocas de denuncia; la accesibilidad que otorgan las redes sociales para hacer pública una situación que nos preocupa en conjunción con una práctica feminista de proteger a compañeras (futuras víctimas) 0 quizás con las características individuales (emocionales o psicológicas) y repertorios disponibles de interpretación/ reacción de cada persona que vive estas situaciones.

Para esto, prestaremos atención a diferentes variables como el género, la orientación sexual de las personas involucradas y la espacialidad (cara a cara, virtual, en ámbitos de esparcimiento, informalidades o formales como una universidad por ejemplo). También hacia otros enclaves de desigualdad como pueden ser la edad y la jerarquía institucional entre las personas involucradas, y sobre los discursos que legitiman o de los que se desprenden los diferentes tipos de respuestas.

Para el primer ejemplo retomaremos la experiencia de Julia con el docente. Las actitudes por parte del docente, a lo largo de la cursada, -descritas anteriormentemotivaron diferentes respuestas por parte de Julia que fueron variando a lo largo del tiempo. Al principio intentó evitar las situaciones que la incomodaban poniendo excusas como "no, no puedo ir ese día", "tengo cosas que hacer", o directamente evitaba darle una respuesta concreta por ejemplo, solía decirle "bueno, vemos...". Sin embargo, cuando el docente la invita a un viaje, ella pasa de lo que podría denominarse una estrategia defensiva a una de mayor confrontación. Le responde de forma contundente que no y además lo bloquea de las redes sociales y abandona la materia. Tiempo después Julia recursa la asignatura luego de asegurarse que la materia sería dictada por otro docente. 
Como mencionamos anteriormente, se puede ver el paso desde una estrategia más defensiva (evasiva) a otra más ofensiva (más explícita y confrontacional) (Osborne, 2009). Al principio se trata más de una evitación de la situación a través de excusas y luego ante la propuesta explícita del viaje, Julia responde de forma contundente. Sin embargo, luego de expresar el no, debió abandonar la materia por miedo a represalias del docente. Raquel Osborne resalta que las estrategias defensivas suelen tener mayor eficacia que las ofensivas, como por ejemplo una denuncia, en donde las razones de la ineficacia son precisamente porque podrían dar lugar a nuevas formas de acoso o represalias por haber respondido y haber hecho visible la situación. Esto es precisamente lo que le sucede a Julia, luego de hacer evidente la negativa, tuvo miedo a las represalias y abandonó el curso.

Aquí debemos tener en cuenta también la jerarquía entre docente y estudiante, la dependencia de la última con el primero (él es quien la evalúa). En este sentido, Osborne resalta que la jerarquía influye en la percepción del acoso, es decir, suele ser más reconocido como tal, por quienes lo padecen. Además, el miedo a las represalias surge precisamente de la dependencia (docente/ estudiante), lo que condiciona fuertemente la respuesta de Julia. Es decir, el cálculo estratégico sobre cómo responder a estas actitudes se abre paso cuando existe la posibilidad de represalia en términos académicos.

En segundo lugar, Julia relata que los hechos desencadenan otra actitud por parte de ella: comentarlo con sus compañeras. Julia comenta lo vivido con compañeras de militancia de la Universidad en un momento en que charlaban sobre algunas actitudes de docentes que las incomodaban. Resalta que, si bien no había tenido una experiencia similar, ella se siente insegura porque el docente "sigue dando clases" y teme que haga lo mismo con otras estudiantes.

Aquí vemos que otra de las reacciones de Julia ante la situación fue contarlo tiempo después a sus compañeras, en un momento de reunión informal y de puesta en común sobre situaciones que habían padecido por parte de sus docentes. Creemos que esta actitud de Julia puede estar influida por su formación y activismo feminista, ya que ella milita en cuestiones de género dentro de la Escuela de Economía y Negocios. Esta actitud se funda en la posibilidad de que el acercamiento del docente hacia ella no haya sido un episodio aislado sino una conducta sistemática del docente, y el entendimiento de esta aproximación como una falta ética debido a la desigualdad de poder entre un docente y una estudiante.

En el contexto actual, teniendo en cuenta la fuerte mediatización del tema y la afloración de denuncias y escraches, la preocupación por parte de Julia -quien ha devenido una activista feminista- que el docente pueda estar acosando a otras estudiantes, podría interpretarse como expresión del contexto en conjunción con una práctica común de la militancia feminista. Marta Lamas explica el pánico sexual, derivado del concepto de pánico moral, como "una reacción desmedida ante cuestiones menores e implica un miedo desproporcionado ante el peligro real de que ocurra lo que se teme" (2018: 56) y a su vez pone en diálogo este fenómeno con el empoderamiento de distintas 
mujeres en los campus universitarios de Estados Unidos en la década de 1980. Con esto no queremos decir que la reacción de Julia sea desmedida, sino que la lectura actual que hace de los acontecimientos puede estar mediada por un clima de fuerte mediatización del tema y por su posterior formación en la temática a través de la militancia.

Al finalizar la anécdota, cuando se le repregunta directamente cómo reaccionó ante esa situación responde lo siguiente:

"dejé de cursar...recién entraba. No conocía este espacio (Consejería) no sabía cuál era el ámbito donde yo podía denunciar esto. No, nunca hice nada... No tenía idea de cómo accionar ante esos casos. (...)No sabía qué tipo de acción, de sanción se le podía aplicar a ese docente" (Julia)

En este último fragmento vemos la valoración de la denuncia como (quizás) la única forma legítima de resolución del conflicto. Esto nos lleva a pensar lo que Tamar Pitch (2014) describe como el vínculo entre discurso feminista y penal. Esta autora plantea que en el momento en que el discurso feminista desliza las nominaciones de las desigualdades de género hacia el concepto de violencia, sin pretenderlo, se produce también un viraje en el foco de las resoluciones a dichos conflictos al plano de lo penal.

Si bien Julia no se refiere a la justicia penal, sino a un dispositivo de atención de la universidad (Consejería integral en violencia de género y sexualidades) traslada las lógicas de lo penal al accionar de este dispositivo. Es decir, habla de asistir a la Consejería "a denunciar" y que por dichas conductas podría caberle "una sanción".

Del mismo modo, la entrevistada expresa su miedo por no poder probar objetivamente lo que se denuncia: "¿qué peso tengo yo en mi palabra como para que...realmente tenga una sanción el tipo? Eso era lo que yo pensaba. (...) solamente por un dicho mío que era real, pero que es un dicho mío" Es decir, se traslada la lógica de la justicia penal y la metodología del derecho.

También resulta visible que hoy en día hubiera reaccionado de otra forma (acudiendo a la Consejería y denunciando la situación) precisamente por los conocimientos que adquirió por su militancia feminista. Lo que refuerza la idea de las consecuencias no deseadas del discurso feminista y su aproximación a algunas lógicas penales a pesar del evidente esfuerzo por complejizar la problemática.

En su conjunto, el relato nos permite suponer la complejidad detrás de las reacciones. Por un lado, el cálculo del costo que podría llevar cada reacción entre las más sutiles de evitación hasta la respuesta negativa directa y contundente. Se puede observar una oscilación entre formas de negativa sutiles que no reporten costos pero que quizás no resuelvan el problema -como las estrategias para evadir las invitaciones que menciona al comienzo de la escena- o formas de negativa más contundentes que tengan costos en otros planos, como por ejemplo en lo académico -cuando decide ser explícita pero inmediatamente después abandona la materia-. 
En el caso de Sonia, ella tenía un vínculo sexo/afectivo reciente con Laura que luego de un tiempo lo calificó como violento. Si bien se trataba de una relación informal de poco tiempo, Sonia empezó a sentirse incómoda con las actitudes de Laura que la hacían pensar que ella intentaba darle a la relación mayor formalidad. En ese momento Sonia decidió cortar la relación, pero Laura continuó intentando acercarse a ella, por lo que Sonia empezó a vivir la situación de forma muy angustiante, calificándola como violenta. Describe que le mandaba muchísimos mensajes, le dedicaba posteos en las redes sociales, intentaba acercarse a ella en diversos espacios, tanto en la universidad como en otros ámbitos donde se desarrolla y en el barrio donde vive.

Las respuestas de Sonia también fueron diversas de acuerdo a cada momento. En un principio intentó comunicarle que ya no deseaba tener ningún tipo de relación ni contacto con ella y que no se acercara a los espacios en donde transitaba, porque la hacía sentir incómoda. Sin embargo, esto no provocó ningún cambio en las actitudes de Laura, por el contrario, seguía contactándola por diversos medios e intentando acercarse a ella.

Luego la bloqueó de todas las redes sociales para que no se pudiera comunicar con ella, sin embargo, tenía conocimiento de que Laura seguía dedicándole posteos de Facebook. Todo esto sumado a que el merodeo de Laura, tanto en la universidad como en el lugar de trabajo de Sonia, se tornaba asfixiante para ella.

En esta instancia y sin que el resto de las actitudes tuviera efecto en Laura, Sonia empezó a hablar con varias compañeras para que la acompañaran en los momentos en que debía cruzarse con ella dentro de la universidad. También sintió la necesidad de hablar con su jefe en el trabajo porque solía aparecerse en la puerta y ella no sabía cómo actuar ante esa situación. Luego habló con dos docentes de las materias en las cuales compartía cursada para que estuvieran atentos. Sonia dice que esto le provocaba aún más angustia, porque tenía que contar intimidades a muchas personas por culpa de Laura.

También se lo contó a su familia y le pidió a su mamá que la llevara y la trajera de distintos lugares en auto para evitar encontrarse con ella. En última instancia y ya desesperada por no evitar encontrarse con Sonia en diversos espacios, le dijo que era muy violenta y que, de continuar cruzándose con ella, la iba a denunciar en la justicia y también en la Universidad. Al poco tiempo la denunció en la justicia y se acercó a la Consejería con la finalidad de no encontrarse a Laura en los espacios de la Universidad.

Pasados unos meses, Sonia se mudó de la casa que Laura conocía. Aunque no lo hizo por esta situación, menciona que el hecho de que Laura no supiera donde está viviendo actualmente la tranquiliza mucho.

En este caso, podemos ver como un rasgo sobresaliente la idea del no contacto, la angustia que genera la simple presencia de Laura y, por ende, el deseo y pedido explícito a distintos actores de mediar para evitar el contacto. 
Tal como describimos, Laura fue avanzando sobre diferentes espacios en los que participaba Sonia. Se la cruzaba tanto en la universidad, como en su lugar de trabajo, en espacios de militancia o en el barrio. Y luego de haber identificado y calificado la situación como violenta, su intención fue no tener que cruzarse con ella en ningún ámbito.

Por este motivo, Sonia habló en su lugar de trabajo, militancia y universidad con el objetivo de que se evitara el contacto entre ellas basándose en su seguridad como "víctima de la situación". Aquí, se unen por un lado la definición de Laura como violenta y una autodefinición de sujeto político en tanto "víctima" de dicha situación (Pitch, 2014). Por otro lado, el traslado de la lógica penal a la situación, ya que el no contacto con Laura se relaciona con resguardar su seguridad, pero de una manera específica: la separación. Como explica Tamar Pitch, la lógica penal tiene una interpretación de la seguridad que consiste en separar "los buenos de los malos", los agresores de las víctimas, que se puede observar en el reclamo contundente de Sonia en los diferentes espacios.

Guido es bisexual y contó dos situaciones diferentes, una con una mujer, Sofía, y otra con un varón, Horacio. En relación con Horacio, lo conoció en la Universidad, cursando una materia en la que Horacio era ayudante de cátedra. Horacio agregó a Facebook a Guido y empezó a hablarle. Guido notó que "le tiraba palos", pero él no estaba interesado. Dijo que el hecho de que fuera tan directo lo incomodaba. Una vez Horacio llegó a publicarle un tema musical en Facebook, la canción hacía alusión a la erotización entre un docente y un alumno. Esto incomodó a Guido, tanto porque sentía la aproximación demasiado directa y explícita como porque era público en Facebook. Sin embargo, dice que eso no lo ofendió, y reaccionó diciéndole en varias ocasiones que "estaba todo bien" pero que no estaba interesado. De hecho, Guido cuenta que le causaba gracia la forma en que Horacio intentaba seducirlo. Actualmente son compañeros en varias materias y no tiene inconvenientes en compartir espacios con él porque "no se zarpó en ningún momento".

A diferencia de los casos anteriores, Guido no califica la situación como acoso, dice que lo incomoda y que le da gracia. Tampoco siente miedo y su respuesta fue una negativa explícita pero cordial.

Sofía, también intentó acercarse a Guido de forma directa y a través de las redes sociales. Un día ella publicó en su Facebook una pregunta relacionada con una materia, Guido le respondió y comenzaron a hablar. Después cursaron una materia juntos y empezaron a tener una relación más fluida. En ese momento, ella se le declaró abruptamente y lo invitó a salir, pero él no estaba interesado y le dijo que no. Luego de eso, Sofía se puso de novia con otro varón de la Universidad y tomó a mal un día que Guido le dice para estudiar juntos. Guido cuenta que amenazó con denunciarlo porque ella tenía novio y él la estaba molestando. En esa ocasión, Guido se enoja y deja de tener contacto con ella, al tiempo Sofía se acerca a pedirle disculpas por haber reaccionado de esa manera y ahora son amigos nuevamente. Actualmente, Sofía suele mandarle mensajes de Whatsapp insinuadores y fotos eróticas para intentar seducirlo. 
En este caso, Guido manifiesta incomodidad, pero deja entrever que no lo vive de forma dramática ni angustiante, solo dice enojarse cuando amenazan con denunciarlo. Es decir, en el caso de Guido, el miedo surge ante la posibilidad de ser "denunciado" (en la Consejería de la Universidad) en una relación heterosexual.

En la comparación entre ambas situaciones podemos inferir que las respuestas de Guido no están influidas por el miedo a su seguridad personal, ni por el miedo a represalias en lo académico y tampoco vivió estas situaciones de forma angustiante, lo que sí caracteriza los casos anteriores. Esta diferencia respecto a los casos de Sonia y Julia no es novedosa y probablemente tenga que ver con el género y las diferencias en las experiencias vividas como varón frente a las experiencias de vida de dos mujeres.

No obstante, lo que resulta llamativo aquí, es el hecho de que sí resulta amenazante para Guido la posibilidad de una denuncia por parte de Sofía. Y esto último, de forma similar al caso de Julia sí podría estar motivado por el contexto actual.

El caso de Vanina, la estudiante travesti, también tiene particularidades que nos hacen pensar cómo las percepciones y reacciones están condicionadas al género de quienes se vinculan. En este caso, un docente con el que había tenido un encuentro sexual, le niega el saludo, le "da vuelta la cara" cada vez que se cruzan en la Universidad. Vanina asocia este hecho con su identidad de género y lo vive como un rechazo y reacciona abandonando la materia.

En la entrevista, Vanina no analiza su reacción, pero podríamos arriesgar que a diferencia de Julia no se trata de miedo a represalias, de hecho, no se infiere de ninguna manera que sienta algún tipo de temor. A diferencia de los casos anteriores, pareciera ser que la motivación del abandono es la incomodidad de encontrárselo en los distintos espacios universitarios y el sentimiento de rechazo que sintió al ver que el docente le negó el saludo.

Siguiendo con la comparación, parece ser que la actitud de Vanina no está mediada por un cálculo de costos que implicaría enfrentar o tolerar la actitud del docente; tampoco pareciera tener que ver con el miedo a represalias académicas, sino que pareciera una reacción casi automática y naturalizada de abandonar el espacio en el cual se sintió violentada o discriminada.

Cabe mencionar que si bien Vanina, con una formación y experiencia de años de activismo, hace una interpretación teórica de la discriminación sufrida, parece no reflexionar políticamente su reacción y simplemente abandona la cursada.

En resumen, durante las situaciones narradas se pueden comparar las diferentes respuestas de las y los actoras/es. Como vimos al principio, éstas varían por diversos factores como es el género de quien los padece, como del/ de la perpetrador/a, el contexto, la afectividad que el hecho desencadena y las experiencias pasadas.

Estas respuestas pueden ir, en el plano de la conciencia y reflexión, desde respuestas sumamente calculadas y estrategias a reacciones de defensa más 
automáticas o naturalizadas. El cálculo costo/beneficio de la mejor respuesta ante cada situación puede tener diversas graduaciones de acuerdo a si se puede o no se puede evitar la confrontación explícita que pueda tener represalias en otros planos.

Las reacciones también pueden variar de acuerdo a las posibilidades que otorgan algunos contextos, como puede ser la formalidad que requiere moverse dentro de una institución como la universidad con una estructura piramidal que pone a las/los estudiantes en desventaja respecto a los/las docentes.

Por último, también pudimos ver como las respuestas de la mayoría de los/las estudiantes están fuertemente atravesadas por conceptos e interpretaciones propias de los discursos y prácticas feministas.

\section{Conclusiones}

En este artículo describimos y analizamos comparativamente, desde una perspectiva interseccional, teniendo en cuenta el género de los actores, la orientación sexual y las jerarquías, escenas de acoso/hostigamiento que tuvieron lugar en el marco de situaciones de seducción y que fueron experimentadas por varones y mujeres que cursan materias de grado en la Universidad Nacional de San Martín. A la luz de este análisis, examinamos cuáles son los efectos que tienen esas situaciones en la subjetividad de las personas que las padecen y qué hicieron frente a esas situaciones.

La reflexión que guio esta investigación se basó en preguntarnos cuáles son los límites entre la seducción y el acoso. En este trabajo realizamos un ensayo de respuesta a algo tan difuso, ambivalente y poroso como es la seducción pensada en los términos románticos que la constituye. Para tal fin pusimos el foco en las dimensiones del consentimiento, sus límites y potencialidades, la espacialidad, esperas y afectividades. Desde esta matriz consideramos que la reiteración, el anonimato, las insistencias, la no respuesta, el miedo a estar con el otro y el avasallamiento son pistas que permiten identificar cuándo la seducción deviene para una de las partes en acoso.

Los casos que problematizamos aquí son, en su mayoría, de militantes o personas vinculadas con el movimiento feminista local, por lo cual poseen redes y espacios de reflexión continuos respecto a la temática del acoso. En el contexto actual nos encontramos ante una mayor visibilización y relectura, por parte de las mujeres, de distintas experiencias de cortejo masculino. Ciertas experiencias que rozaban los umbrales del acoso y que antes eran naturalizadas, hoy están siendo puestas en el tapete y debatidas a la luz de las lecturas sobre la violencia de género. En este marco hay un incremento de las denuncias, escraches y relatos de situaciones de seducción que devinieron en escenas de acoso.

Consideramos que estas nuevas relecturas militantes y feministas sobre los cortejos están habilitando a repensar los umbrales de lo deseable dentro del cortejo, que en su configuración romántica se ha basado en la porosidad y la ambivalencia, lo cual ha 
Revista Punto Género № 12. Diciembre de 2019

ISSN 0719-0417 / 48 - 72

permitido formas sutiles de hostigamiento en detrimento de los cuerpos femeninos. No obstante, desde una mirada atenta a este nuevo contexto estamos alertas ante una avanzada punitivista, por parte de los feminismos. Las respuestas punitivistas son en sí mismas androcéntricas y liberales, a su vez que desde una lectura del poder habilitan resistencias masculinas que van en contra de las propias mujeres.

El desmantelamiento de guiones de cortejo basados en el hostigamiento de los cuerpos femeninos es de largo alcance, requiere de análisis y estrategias militantes, en diversos ámbitos, incluidos los institucionales, que problematicen y propongan pedagogías eróticas feministas que pregonen por el respeto a la autonomía de los/as otros/as y descentralicen los vínculos erótico-afectivos como el centro de las vidas de las personas. Por último, a partir del análisis se desprende que los guiones románticos heteronormativos que hacen pendular al erotismo hacia el acoso, aunque con sus particularidades, pueden darse en el marco de parejas no heterosexuales.

\section{Bibliografía}

Appadurai, Arjun (1986): La vida social de las cosas. Perspectiva cultural de las mercancías. México DF: Grijalbo.

Barthes, Roland (2007): El placer del texto. Madrid: Siglo XXI.

Butler, Judith (2011): "Some thoughts on psychoanalysis and law", en Columbia Journal of Gender and Law, Vol. 2, No. 2.

Collins, Randall (2009): Cadenas de rituales de interacción. Barcelona: Anthropos, UAMAzcapotzalco, UNAM-FCPY, Editorial Universidad Nacional de Colombia.

Connell, Raewyn (1995): Masculinities, Berkeley: University of California Press.

Crenshaw, Kimberle (1998): "Demarginalising the intersection of race and sex. A black feminist critique of antidiscrimination doctrine, feminist theory and antiracist politics", en University of Chicago legal forum, No. 14, p. 538-554.

Cochrane, Kira (2013): All the rebel women: The rise of the fourth wave of feminism. London: Guardian Books.

French, B. H. (2013): "More than Jezebels and freaks: Exploring how Black girls navigate sexual coercion and sexual scripts", Journal of African American Studies, 17, p. 35-50.

Haraway, Donna (1991): Ciencia, cyborgs y mujeres. La reivindicación de la naturaleza. Madrid: Cátedra. 
Revista Punto Género № 12. Diciembre de 2019

ISSN 0719-0417 / 48 - 72

Illouz, Eva (2012): Por qué duele el amor. Una explicación sociológica. Buenos Aires: Katz.

Kaufmann, Jean-Claude (2012): Love online. Cambridge: Polity Press.

Kóczé, Angéla (2011): La stérilisation forcé des femmes roms dans l'Europed' aujourd'hui. Genre, modernité et "colonialité" du pouvoir, en Cahiers du Gendre, No. 50, p. 133-152.

Lamas, Marta (2018): Acoso ¿Denuncia legítima o victimización? México: FCE.

Lefebvre, Henri (2013): La producción del espacio. Madrid: Capitán Swing.

Marentes, Maximiliano; Palumbo, Mariana y Boy, Martin (2016): "<<Me clavó el visto>>: los jóvenes y las esperas en el amor a partir de las nuevas tecnologías", en Astrolabio, No. 17 , p. 307- 330 .

Matos, Marlise (2010): "Movimento e teoria feminista: É possível reconstruir a teoria feminista partir do Sul global?", en Revista de Sociologia e Política, Vol. 18, No. 36, p. 6792.

Meccia, Ernesto (2012): "Subjetividades en el puente. El método biográfico y el análisis microsociológico del tránsito de la homosexualidad a la gaycidad", en Revista Latinoamericana de Metodología de la Investigación Social, Vol. 4, No. 2, p. 38-51

Moore, Allison, y Paul Reynolds (2004): "Feminist approaches to sexual consent: A critical assessment". en Cowling, Mark y Reynolds, Paul (ed.): Making Sense of Sexual Consent, p. 29-43. Hampshire: Ashgate

Osborne, Raquel (2009): Apuntes sobre violencia de género. Barcelona: Bellaterra

Paiva, Vera (2006): "Analisando cenas e sexualidades: a promoção da saúde na perspectiva dos direitos humanos", en Cáceres, Carlos; Careaga, Gloria; Frasca, Tim y Pecheny, Mario (eds.): Sexualidad, estigma y derechos humanos: desafíos para el acceso a la salud en América Latina, p. 23-51. Lima: FASPA/UPCH.

Palumbo, Mariana (2018): "Solas y solas: búsquedas de encuentros eróticos y afectivos en mujeres y varones heterosexuales (Área Metropolitana de Buenos Aires, 2015-2017)". Tesis (Doctorado en Ciencias Sociales). Ciudad de Buenos Aires: Universidad de Buenos Aires, Facultad de Ciencias Sociales.

Pérez Hernández, Yolinliztli (2016): "Consentimiento sexual: un análisis con perspectiva de género", en Revista mexicana de sociología, Vol. 4, No.78, p. 741-767. 
Revista Punto Género № 12. Diciembre de 2019

ISSN 0719-0417 / 48 - 72

Pitch, Tamara (2014): "La violencia contra las mujeres y sus usos políticos", en Anales de la Cátedra Francisco Suárez, No. 48, p. 19-29.

Ronen, Shelly (2010): "Grinding On the Dance Floor: Gendered Scripts and Sexualized Dancing at College Parties", en Gender and Society. No. 24, p. 355-377.

Simmel, Georg (1961): Cultura femenina, y otros ensayos. Madrid: Revista de Occidente.

Simmel, Georg (2003): Cuestiones fundamentales de sociología. Barcelona: Gedisa. 